\title{
Transverse Reflexive Simulation: a method for anchoring human activity at the heart of the company's performance
}

La Simulation Réflexive Transverse : une méthode pour ancrer l'activité

humaine au cour de la performance de l'entreprise

Florence Motté and Céline Poret

\section{(2) OpenEdition}

\section{Journals}

Electronic version

URL: http://journals.openedition.org/activites/4896

ISSN: $1765-2723$

Publisher

ARPACT - Association Recherches et Pratiques sur les ACTivités

Electronic reference

Florence Motté and Céline Poret, «Transverse Reflexive Simulation: a method for anchoring human activity at the heart of the company's performance », Activités [Online], 15-1 | 2018, Online since 15 April 2018, connection on 30 December 2019. URL : http://journals.openedition.org/activites/4896

This text was automatically generated on 30 December 2019 .

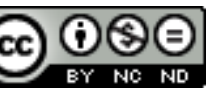

Activités est mis à disposition selon les termes de la licence Creative Commons Attribution - Pas d'Utilisation Commerciale - Pas de Modification 4.0 International. 


\title{
Transverse Reflexive Simulation: a method for anchoring human activity at the heart of the company's performance
}

\author{
La Simulation Réflexive Transverse : une méthode pour ancrer l'activité \\ humaine au cour de la performance de l'entreprise
}

Florence Motté and Céline Poret

\section{AUTHOR'S NOTE}

Current attachment: Institut de Radioprotection et de Sûreté Nucléaire - Fontenay-auxRoses - celine.poret@irsn.fr

\section{Introduction}

1 For the last twenty years, competitive pressures have existed in all areas of business. Companies looking to increase performance are very often still relying on industrial models even though they are tending more and more towards service activities (Du Tertre, 2007). The switch towards such activities disrupts the service relationship of these companies and impacts the skills of which it is composed, the way they are organised, the tools that are used and the number of actors involved; customers themselves thus become actors in their own right. "

2 Against this background of increasingly complex service relationships, EDF (Électricité de France) has also committed to this change and is looking to improve its performance while at the same time maintaining the quality of its service. It is within this framework that an ergonomics technological research programme known as "service 
relationship engineering" has been developed (Motté \& Haradji, 2010) over recent years in the R\&D department. The purpose of the programme is to understand the service relationship in all its complexity, by attempting to characterise the different activities involved and to be creative in order to help these activities. Its premise is that by taking human activity into account one can identify the performance indicators that will enable the company to differentiate itself.

3 By placing our work within a technological research programme (Theureau, 2006; Poizat \& Durand, 2015) we give it strong cohesion whilst at the same time leaving room for questions and scientific innovations. This fits in with the concerns of our customers' management teams and leads to cross-fertilisation between research and operational projects. We are thus in a long-term dynamic that is designed to help with the company's transformation.

4 The cornerstone of this programme consists in highlighting a transverse and collective activity that is crucial for the understanding and improvement of the service relationship even though this activity is not visible to organisations, due to it being distributed throughout time and space. This article presents our most recent study, in which we tried to make this activity visible and to detect levers of transformation with which to make the service relationship simpler and more fluid. This resulted in the Transverse Reflexive Simulation method, and over the course of its development we worked with customer service advisers ${ }^{1}$ to simulate the processing of a customer's request from $\mathrm{A}$ to $\mathrm{Z}$.

5 This simulation is the result of the research programme and of the various studies that preceded it. This is why we begin this article with a presentation of the foundations of the research programme and of the knowledge gradually acquired and questions raised with regard to the characterisation of the activities implemented as part of the service relationship and the possibility of understanding the point of view of the advisers and customers. We then describe the objectives that led us to perform the simulation, the elements that enabled us to develop the method, and finally the method itself (a simulation in two parts). After setting out a certain number of results from the implementation of the Transverse Reflexive Simulation, we discuss the benefits of this method.

\section{A project rooted in an ergonomics research programme}

\subsection{A technological research programme on service relationships within the commercial sector}

6 The research programme of which the study presented in this article is a part, takes place within EDF's R\&D division and concerns service relationships in the commercial sector. It intersects with the requirements of commercial management teams, be it for the business market or for the individual customer market; it examines the activity of both the advisers working in the Customer Service Centres (CSC) and the activity of EDF's customers. There are just over 6,000 advisers working on the business or individual customer markets. To give an order of magnitude, all channels together, every year individual customers make the following requests: 3.2 million for 
connection, 1.5 million for a change of contract and 3.2 million for termination (to name just these types of request).

7 This ergonomics research programme is centred around two inseparable axes: a theoretical and scientific axis aimed at understanding human activity and a technological axis in order to be creative and promote this activity. Our proposed changes serve three simultaneous objectives: customer satisfaction, the conditions for carrying out the actors' work, and the company's performance. This R\&D programme is also designed to acculturate the Business Management team with whom we are working, to help them evolve and contribute towards these improvements.

Our theoretical framework is embedded within the constructivist paradigm of human cognition, which considers that the latter is not predetermined but rather that it creates itself in situ in relation to the environment (Varela's enactment paradigm, 1989). Against this background, and by giving a central role to the actor's point of view, our methodological position consists in considering individual activity and collective activity in a single movement. In this respect we follow methodological situationism (Theureau, 2006) which sees collective activity as the interlinking of the individual activity of the different actors. By individual activity we mean an activity that always includes other actors and that Theureau (2006) describes as "social-individual". Hence each actor's point of view is not only individual, it is "social-individual" because it constantly takes into account the activity of other actors In order to act himself.

\subsection{A long-term process that ensures progression in terms of knowledge and lines of enquiry}

9 This research began in 2005 and has developed in line with new lines of enquiry and work opportunities with our business management teams, constantly interlinking research matters with operational issues. The purpose of this chapter is not to set out all of the results, but instead to briefly present the aspects of our knowledge progression and lines of enquiry that led to and served as a basis for the study described in this article. These are illustrated in figure 1 and set out in the new part of this section.

Figure 1: Progress of the ergonomics research program for the EDF service relationship Figure 1: Progression du programme de recherche en ergonomie pour la relation de service à EDF

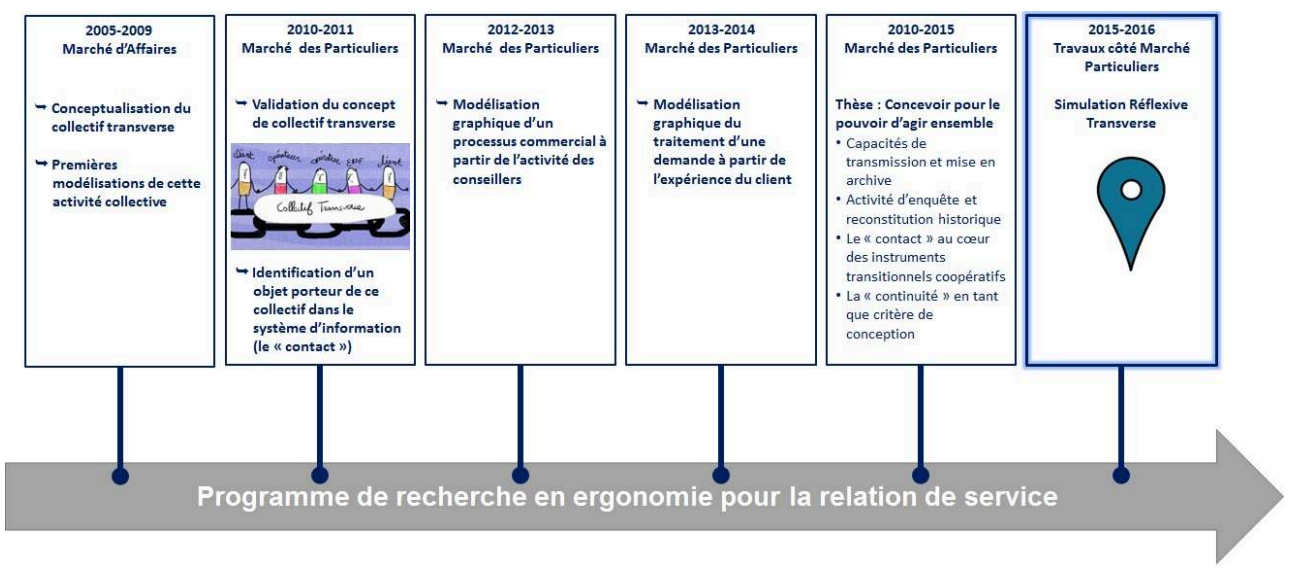




\subsubsection{Conceptualisation of the transverse collective; initial modelling of this collective activity (2005-2009)}

10 The first works on the service relationship were carried out for the business market and focused on the activity of the advisers working there. Our observatory initially concentrated on the online salespeople (Motté \&, Haradji, 2007), then on the customer service personnel (contractualization, invoicing) and finally on the connection managers (link with energy distributors). Our analyses thus related to the work done within each department.

11 We very quickly realised that it was not enough to analyse activity by job type in order to study service relationships and that the latter result from the work done by different actors, each of whom, depending on their job, performs part of a whole, culminating in a response to the customer's request (Motté \& Haradji, 2010; Motté, 2012). This result led us to change the objective of our study, so as to understand the human activity and bring it to bear on the customer's request. We demonstrated that the processing of the request results from the intersection of the individual activities of the various actors working at different times and in different places; we describe this collective activity as transverse collective activity (Motté \& Haradji, 2010; Motté, 2012; Poret, 2015).

Understanding transverse collective activity is a complex matter, because it is not concentrated into a single place or time, and is unpredictable in as much as we do not know when the next stage of the process will take place, nor in most cases where (except in the case of a given adviser portfolio). This complexity is increased by the large number of customers and even more so by the number of requests they can make to EDF. So it is impossible to monitor the processing of a single given request. To model transverse collective activity based on observations of adviser activity therefore requires one to reconstruct the processing history of a type of customer request by juxtaposing different parts of the request and the related activity (Motté 2012). Like Grosjean and Lacoste $(1999$, p53) when they studied activity in hospitals, we had to make methodological choices: "Most studies on collective work examine the situations in which operators are present together within the same space, or else cooperation between clearly identified intermediaries working in different places. This relative reduction in complexity makes it possible, at the methodological level, to avoid certain difficult choices. On the other hand, complex collective functioning involving numerous actors in numerous situations is challenging for researchers, because it forces them to segment and recompose an object whose reality remains forever elusive."

\subsubsection{Validation of the concept of transverse collective; identification of an object acting as a channel for this collective within the information system (2010-2011)}

This time work focused on the individual customer market and more especially on the Direction des Information Systems Management Team. They were tasked with how the evolution of the Customer Relations Management software (CRM) impacted adviser activity. Once again, it was impossible to observe the different stages of a single request. To analyse adviser activity in the front office and back office, we therefore had to build our data collection in order to understand how a given actor's activity is constructed in the here and now and in what way it contributes towards a collectivetype activity for effective request processing (Motté, 2012). To this end we made the 
methodological decision to position ourselves within the theoretical and methodological framework of the course of action which "makes it possible to understand the construction of the collective activity using the significations constructed by each of the actors during their interactions in a given situation" (Theureau, 2004). These works made it possible to validate the concept of transverse collective within a given profession - that of an adviser who processes different parts of different requests but never different parts of the same request. The existence of the transverse collective and the interlinking between actors take form through the traces that they each leave in the information system, for example with an object of the CRM called "contact", linked to a "commentaire"2 field (Cf. further details in 2.2.5).

\subsubsection{Graphic modelling of a commercial process based on adviser activity} (2012-2013)

The individual customer Business Management Team was reviewing its processes with a view to simultaneously optimising customer satisfaction, economic performance, sales and debt recovery. To this end, the RTM (Register, Terminate, Modify) process manager decided to use mapping to see what was happening. To help him do so and to root human activity in said mapping, we used our previous studies, taking as an entry point the customer request and the individual and collective activity that took place therein, using the previously gathered data for a second time.

Figure 2 illustrates the principles behind this mapping. We represented the processing of the customer's request in the form of a historical chronology, i.e. horizontally. Our mapping began when the customer contacted EDF; the end of the mapping was the moment when the customer considered the request to be fully terminated. We thus offered a global vision of the processing from start to finish and demonstrated that a customer's request for connection involves far more than just the registration stage considered at the beginning by the process team. This representation revealed the contributions made by the various advisers, by the distributor and by the customer with whom EDF has both incoming and outgoing communications (billing in particular). We listed the different computer applications that were used, without detailing the actions that were required because we were targeting a long-term mapping even should modifications to these applications be needed. Lastly, we identified the variabilities that might slow or block the processing, along with additional processing stages should any anomalies be detected. 


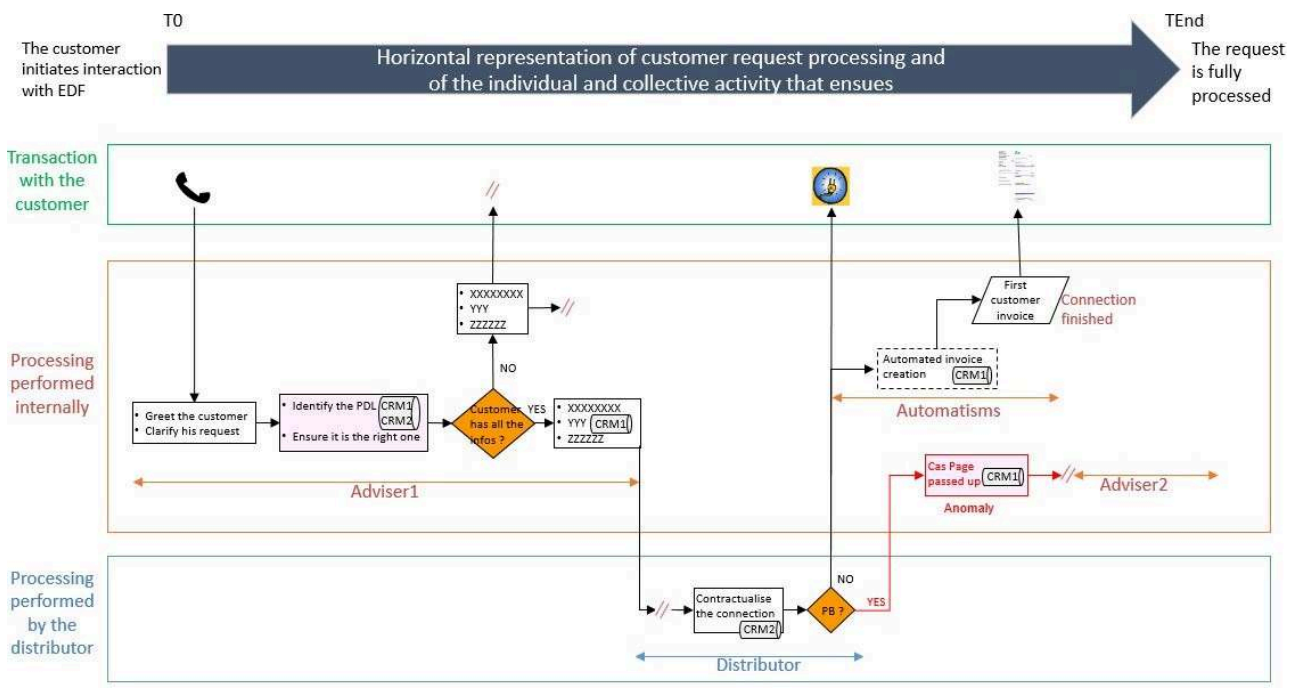
activity. While remaining in the framework of the individual customer market, we chose to examine it from the customer's viewpoint. From the outset there was one methodological question: how to build our data collection in order to reconstitute, as close to reality as possible, the customer's experience throughout the processing of his/her request for an EDF energy connection? To resolve this issue we developed a new data collection methodology, with individual sessions at the homes of customers whose requests dated back less than two months and had been completed. This methodology encouraged customers to engage in a series of increasingly precise narrations, putting themselves back into the situation and remembering their interactions with certain actors in the service relationship or in their own environment.

In this way we graphically modelled the customers' stories from $\mathrm{A}$ to $\mathrm{Z}$ and their various interactions with EDF or other actors (distributor, owner, family, neighbour, etc.), the information that was exchanged, the contact channels used, etc. We also included the customers' emotions (that we had managed to access while gathering data) throughout the processing of their request. On the EDF side we had access to the traces left in the "contact" section of the CRM software. Entry via the customer's request rather than via the contact channel used by the business management team, allowed them to identify how the customers used the different channels to move their 
requests forward and their expectation of both coherency between channels and of processing fluidity. This highlighted the need to begin to work to enable the processing and multi-channel follow-up of customer requests.

\subsubsection{Designing for the power to act together in a transverse collective (ergonomics thesis) 2010-2015)}

Céline Poret (2015) wrote a thesis that also fuelled the project work that was carried out. She began with a study for the Information System management teams, which allowed her to collect field data; she also helped with the mapping of the commercial process.

This thesis highlighted the fact that the transverse collective activity at the heart of the process consists in interlinking, at each stage, the historical reconstruction, the introduction of a plot and transmission, and the archiving. In order to continue the processing of a request that has already been initiated, advisers need to access past aspects of the request, and to do so, they carry out an investigation. The result of the investigation must allow them to reconstruct the timeline of the events that took place during the processing of the request; like historians, they thus attempt to resolve "intrigues" (Veyne 1971) that differ in accordance with the stage that is being processed. Having resolved the intrigue that allows them to understand the history of the request processing, they process that stage and lay the ground for the next; one of their preoccupations is thus to coordinate their own activity with that of the other actors in the process.

To achieve this coordination, the advisers took ownership of the technical and organisational system and built "cooperative transitional instruments" (Poret, 2015; Poret \& al, 2016). The main ingredient mobilised in these instruments consisted of the "contacts" left in the CRM software and more particularly of the "commentaire" made by the advisers. The "commentaire" left by the actors during the previous stage of the processing of the request allow the adviser in charge of the current stage to reconstruct the processing history and thus take on from there. In turn, he leaves a comment that will serve to transmit (or archive) elements relating to his/her activity, here and now, for the actors who will subsequently be processing the request. The comment thus allows subsequent actors to reconstruct the history, and so on and so forth until the request has been fully processed. If one adopts the overall plan for the request, these instruments therefore give the processing continuity, despite the discontinuity of the different contributions of which it is comprised. After highlighting these instruments, proving the existence of this transverse collective activity prior to the intervention by the researchers, the thesis examined the conditions which made their mobilisation more complex - or even impossible ${ }^{3}$. These results made it possible to define a criterion for technical and organisational design: the continuity criterion. In proposing this generalisable design criterion, the aim is to go beyond the stage of local adjustments specific to a given technical-organisational environment, in order to drive a lasting movement of transformation in accordance with a transverse logic. 


\section{Transverse Reflexive Simulation - Presentation of the method}

\subsection{Principal objectives}

At this stage of the research programme we felt that the company had reached the limits of a system that does not enable one to take account of the overall performance of an activity that is temporally and geographically segmented. Moreover, we realised that the maximisation effects at the local or individual level (number of calls per hour, for example) might even work against overall optimisation or customer satisfaction. The process manager lacked the resources and tools with which to respond to this situation and to monitor service quality throughout the entire process, especially when the customer is using different channels for a single request.

The various studies we carried out in conjunction with the Business Management team on the service relationship and on highlighting the transverse collective finally raised our colleagues' awareness of this notion. The next step was to bring it to life within the organisation and the technical system. Indeed, this transverse collective is based on a work of coordination between actors (Strauss, 1992) and constant adjustment. However, "this "additional" work is often invisible and in any case is to a large extent underestimated compared to the directly productive activities that it nevertheless conditions".

Our first objective was therefore to reveal the transverse collective and create the conditions for its development by working on the continuity of request processing. This continuity relates not only to the coordination between the different actors (customer included) but also to the visibility of the automated segments of the process. We also wanted to focus on an essential element of continuity in the information system, i.e. the "contact" whose importance had been highlighted in the previous studies. As ergonomists, the point of revealing the activity is to transform/improve the process (in the context that concerns us here) in order to support this activity. It is thus a case of providing feedback on the aspects that support or hinder the continuity and fluidity of the processing of a customer's request. There was also the potential improvement to the quality of adviser training, by highlighting the transverse collective and its continuity in complex situations (multi-channel, unforeseen events on the customer's side, etc.).

\subsection{Method construction}

\subsubsection{Initial questions to define the method}

The particularities of the transverse collective are that it develops over time as the processing of the customer's request moves forward, and that it is fragmented, with the actors working at different times and in different places. For it to be revealed, one solution is to put the actors together (Lorino \& Peyrolle, 2005; Arnoud, 2013) but this means that the complexity of the work being done as the process moves ahead is lost. To trace back the work actually done, one therefore needs to create the conditions for simulating it, by simulating the processing of a single customer request. To this end we wrote a script describing request processing situations that gave us case studies to play out and analyse with actors from the collective. The advantage of this methodology is 
that it gives concrete form to a work collective by bringing everyone involved with the request into the same place at the same time; it creates the conditions for reflexivity in relation to their work and allows them to see something they would never otherwise see: the global nature of request processing. In this way it provides feedback on the process as a whole and reveals the coordination that is required between the actors. The CSC teams regularly work on "critical" cases in order to teach advisors about good processing practice but inter-personal coordination is not examined, to such an extent that the process manager stressed the utility of this new prism of analysis that we were suggesting. We also examine the cognitive aspects of the activity, looking at the "deeprooted causes ${ }^{41}$ that lead to a request being processed in a particular manner; our aim is not therefore to study the "correct processing of cases". Just like the "In-depth Event Analysis" ${ }^{5 "}$ used in the nuclear sector (ICSI "Event Analysis"6 exchange group, 2013; RON, C., 2012) our objective is to reveal the real work, the day-to-day work, be it individual or collective activity, and to envisage the possibility that organisation, procedures, tools, etc. might hinder work and be at the origin of these "deep-rooted causes". So we are not placing ourselves in the realm of "human error" or of "noncompliance with procedures". The identification of deep-rooted causes provides levers of transformation and makes it possible to aim for a more effective operation of the collective and hence of the process, while at the same time ensuring processing quality. A prerequisite for identifying these deep-rooted causes is to establish a climate of trust and freedom of expression.

\subsubsection{Simulated activity: full processing of a real customer request}

Revealing the transverse collective and examining the coordination between actors obviously meant working on a request from start to finish. We wanted to show how a malfunction affects people's work, the fact that it might be "invisible" when it takes place during the first stage and how the following stages pile up during the processing of this same request. We also wished to include the customer's point of view from a broader standpoint than just at the end of a processing stage and access his/her experience over the request as a whole.

The problem was the direction in which the request should be played out. To make an outright announcement of what had occurred and then move backwards over the different stages would not reflect the reality of the segmented process and of the coordination between actors. We would no longer be able to talk about activity simulation and there was the risk that this would mean it was more of a reminder of the procedures than an identification of the deep-rooted causes. We therefore opted for a dynamic identical to the reality, by starting at the beginning, with the first contact with the customer.

31 In order to simulate advisor activity we worked on two real requests that were fully processed on the EDF side and on the customer side. Because we were working on the transverse collective, these requests had to involve several stages of processing by the advisers. We felt that there had to be at least three such stages. For the requests to be useful In terms of simulation, they needed to include elements of criticality and typical malfunction in the connection process. The best way to find such requests was to look at those that had been the object of complaints. The choice was then made on the basis of the concerns of the Business Management team (multi-channel for example) and of 
the possibilities found among recent requests. The following two requests were thus selected:

Connection completed without the customer, after a disconnected phone call, followed by modification to tariff-related advice (request 1 ),

Connection initiated on the internet and then performed by an adviser due to an internet bug (request 2).

During their work, advisors sometimes have to deal with a customer request that is new or ongoing. In the latter case they become involved at different stages of the processing and it is their job to determine what the customer requires, what has already been done and what remains to be done. For this reason, for each request selected for the simulation, we identified the stages of the request that were processed by the advisers and each of these stages was made the object of a scenario to be played out with the advisors (without telling them that they were scenarios relating to the same single request). We thus had three scenarios to play out for each request. As an example, these were the scenarios for the first request:

The customer calls but is not recognised by the call management system. He has to do some home renovation in his new house and has realised that there is no electricity. He wants to complete the formalities and can provide the address of the property. Just when the advisor says he wants to discuss tariffs, the phone call is cut off.

The caller says he has received a bill following a request for connection. He now has electricity but the contract power is $6 \mathrm{kVA}$ whereas he wanted $12 \mathrm{kVA}$. Because such a change requires the intervention of a technician, the adviser has to organise an appointment. Once the appointment has been made, the customer says that the question of level of power had not been raised during his initial call and that he does not wish to be billed for the second intervention.

The customer calls because he does not understand why he has received bills relating to a tariff change given that he did not receive confirmation of the appointment made during a previous call to have the contract power increased (from 6 to $12 \mathrm{kVA}$ ). Furthermore, there is no mention of the gesture of goodwill he had been promised.

\subsubsection{A historical reconstruction essential to the creation of Transverse Reflexive Simulation}

In order to simulate the activity we need to understand what happened in relation to each of these requests at the various stages of the A to $\mathrm{Z}$ processing, on both the EDF side and the customer side. It was therefore necessary to reconstruct the history of the request processing. As our previous studies had shown that the historical continuity of the activity can be reconstructed using the information systems, we worked with an expert in this field to analyse the information and traces left in the information systems relating to the request and its processing. This allowed us to understand how events might have unfolded, the interventions of the various advisers, the customer, the distributor, etc. This expert thus carried out the same enquiry (Poret, 2015) that advisers perform to reconstitute the history of a customer request when they take on the case. The difficulty experienced by the expert when doing this work "at his leisure" demonstrates just how complex it is for the advisers to perform the historical reconstruction that is so vital to request processing when they are working in the heat of the moment and the customer is on the phone. 
In addition to the need to understand request histories, such work must also make it possible to reconstruct the different states in which the information system found itself at each stage (scenario), so as to "re-establish" screen content as it might have been at the stage one wishes to play out, and to have access to the important elements to give the advisers. Because the information systems were ever-present during the advisers' activity, it was unthinkable to disregard them during the simulation. In order to create realistic conditions for playing out scenarios it was important to reconstitute the work context for each simulated stage. As certain pieces of information (such as the "commentaire" left by the advisors) were historically recorded, it was easy to see which information to present during the stage in question. On the other hand, as a certain amount of data was entered to replace other data, it was far more complicated to know which information related to the stage in question and to recreate screen content that accurately represented the situation as it must have occurred. Only knowledge of the profession allowed us to make a decision on this matter. Once identified, this information was reproduced in paper form so that the scenarios could be played out during the simulation sessions. Figure 3 shows the contact-related "commentaire" zone that the advisers used in the CRM software.

Figure 3: "Commentaire" zone linked to "contact" in CRM software

Figure 3: Zone du " commentaire » associée au « contact » dans le logiciel de CRM

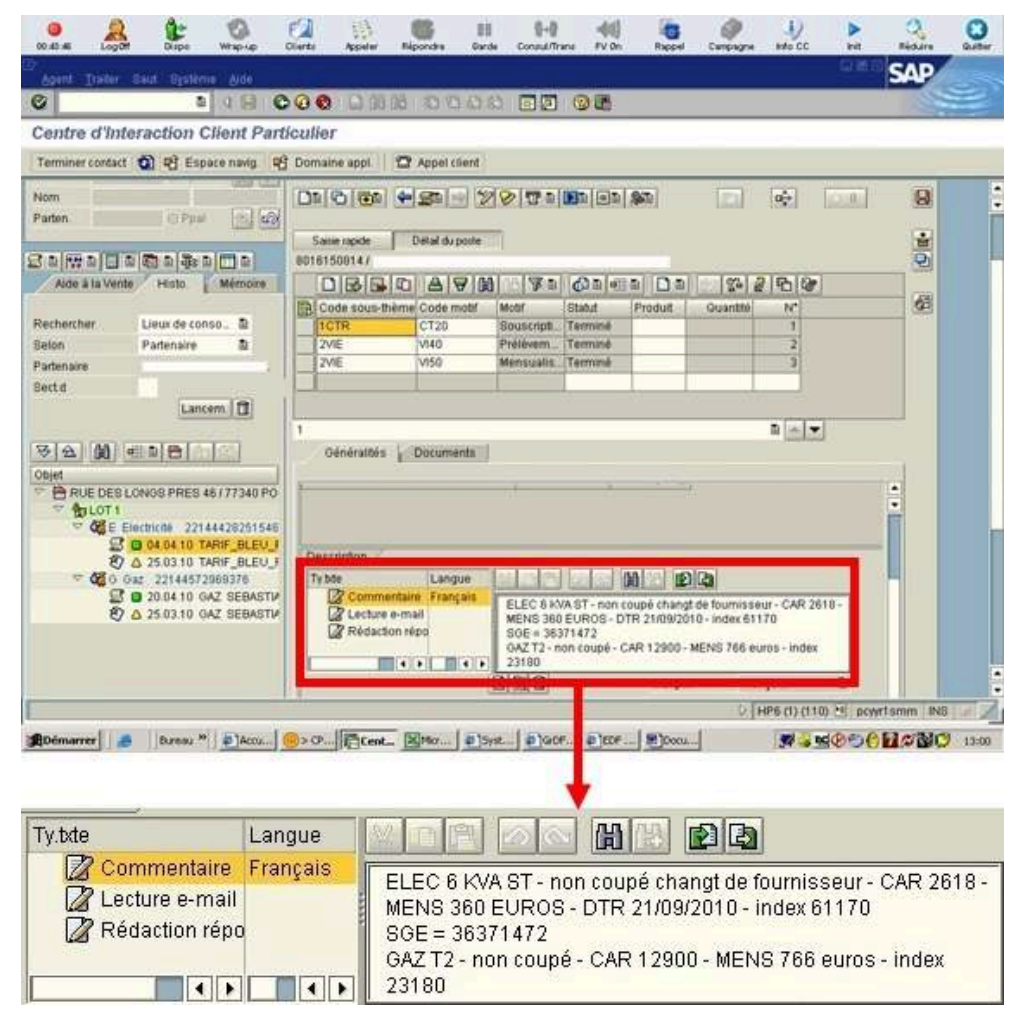

Figure 4 shows a "commentaire" presented to the advisors during the second scenario of request 1 (connection completed without the customer following a disconnected phone call).

Figure 4: "Commentaire" from the second scenario played out for request 1 Figure 4: «Commentaire » du deuxième scénario joué pour la demande 1 


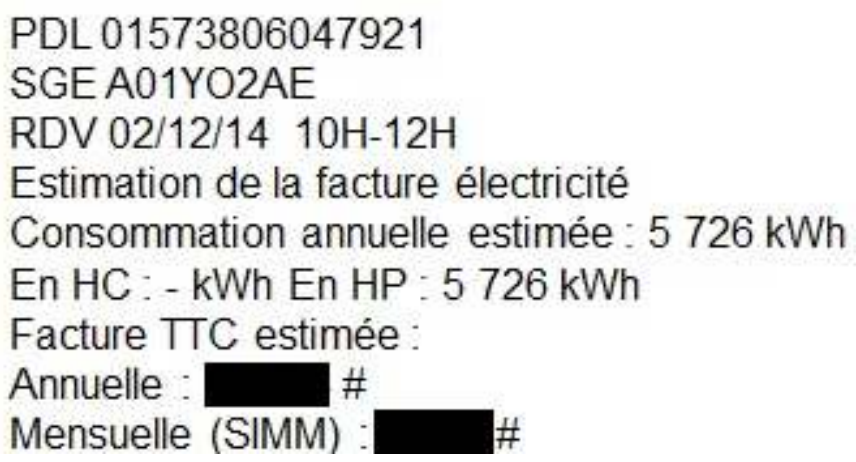

\subsubsection{The actors involved in the sessions}

41 The advisers were the objective of our simulation and as such they were the first to be involved in the sessions. Because request processing brings different profiles into play (in both the front and back offices) relating to various different activities, we wished to reproduce these characteristics. It is for this reason that the first criterion for the sessions was the diversity of adviser profiles: mobility (everything relating to the termination or opening of a contract, ongoing relations (explanation of bill, payment by bank card, contract modification, etc.), dual competency (mobility + ongoing relationship), complaints, contact person for connection by the customer via the internet).

42 In order to bring out the real day-to-day work and the possible organisational and technical constraints, it was important that the advisers had total freedom of expression. The second criterion was therefore that for a given session they had to come from different CSCs. We also wanted to include advisers working as service providers in specific CSCs, but unfortunately for regulatory reasons this was not possible.

Regarding this requirement of freedom of expression, upon reflection we decided not to include management in the sessions. Indeed, "a hierarchical link between participants can influence verbalisations. This should be taken into account when organising meetings." (ICSI "Event Analysis" exchange group, 2013).

As our study has points in common with the In-Depth Event Analysis used in the nuclear sector (ICSI "Event Analysis" exchange group, 2013; RON, C., 2012) we considered the pertinence of including advisers involved in the request processing being "played out" in the simulation. The extremely high number of requests processed and the no-risk nature of the requests (unlike in the nuclear sector) means that there is no memory of the cases processed and as a result there was no point in including the advisers who had actually processed the request.

Non-EDF actors (electricity and gas distributors) are also involved in customer request response. As was the case for service-providing advisors, due to regulations it was not possible to include them in the simulation. To make up for their absence, we used the traces and information available in the information systems to recover their activity.

The customer was an inescapable element in the simulation but the question was whether or not he should be physically present during the sessions (we are not talking about the customer in the absolute but about the customer whose request was going to be played out). We must not forget that we were targeting the everyday work done by 
the advisers, and not the "correct" processing of the request; this would have been difficult or even impossible if the customer had been present, especially as he would not necessarily have understood that we were not specifically looking to explain what had happened and what should have happened in relation to his request. But while the customer's presence was not conducive to the objectives, his contribution was essential. We therefore looked to recreate the experiences of the two customers in relation to their respective requests and their processing. To this end we used the method we had developed for our study on customer experience when moving home and we contacted each of the two customers concerned by the requests to be played out in the simulations. In this way we were able to understand their points of view and their emotions relating to their requests.

The reconstruction (via the information system) of the request processing history along with the elements obtained from customers allowed us to create a graphic modelling of the processing of each of the two requests on the same basis as those illustrated in figure 2. These representations allowed us to perform an additional activity simulation based on the scenarios mentioned above. In the next section we explain how the activity simulation sessions took place.

\subsection{A simulation in two complementary parts}

In order to identify any potential differences, each of the simulated requests were the object of two sessions with different teams. Three advisors, different each time, participated in each session. These elements are summarised in table 1 below.

Table 1: Diversity of profiles and Service Relationship Centres (SRC) of the customer service advisers involved in sessions

Tableau 7: Diversité des profils et des CSC d'appartenance des advisers participant aux sessions

\begin{tabular}{|l|l|c|l|c|}
\hline & \multicolumn{2}{|c|}{$\begin{array}{c}\text { Request 1 } \\
\text { Profiles }\end{array}$} & CSC & \multicolumn{2}{c|}{$\begin{array}{c}\text { Request 2 } \\
\text { Profiles }\end{array}$} & CSC \\
\hline \multirow{3}{*}{ Session 1 } & Mobility & A & Internet contact person & A \\
\cline { 2 - 5 } & Dual competency & B & Complaints expert & D \\
\cline { 2 - 5 } & Complaints expert & C & Ongoing relationship & $\mathrm{A}$ \\
\hline \multirow{3}{*}{ Session 2 } & $\begin{array}{l}\text { Internet contact person + } \\
\text { Recent dual competency }\end{array}$ & A & Internet contact person & $\mathrm{A}$ \\
\cline { 2 - 5 } & Complaints expert & D & Dual competency & C \\
\cline { 2 - 5 } & Dual competency & D & Complaint & B \\
\hline
\end{tabular}

Each session lasted for approximately three and three-quarter hours, split as follows:

- Introduction: presentation of the participants, the tasks and how the session would unfold (15 minutes).

- Part 1: simulation of the processing of the segments of a customer request (90 minutes).

- Pause (15 minutes).

- Part 2: simulation of the actual processing of a request (90 minutes).

- Session feedback: what the advisers thought (15 minutes).

During the introduction there was a presentation of the key points of the research programme, the partnership between the R\&D and Business Management teams in this respect, and the objectives of the study. We informed the advisers that we were going to work both individually and collectively on the case studies and that we were not trying to identify "correct" processing, but rather to use these cases to evoke their 
everyday work situations. Our aim was to hear diverse points of view so as to identify avenues for improvement.

\subsubsection{Part 1: simulation of the processing of the segments of a customer request} prociner. In order to get to grips with the case to be processed, each adviser was with a trainer who played the role of the client; to create realistic conditions and provide a contextual anchor, he also had paper printouts of screen content illustrating the information systems. The advisors were asked to try to understand the case and to process its broad aspects by using the screen contents when so needed and by asking the same questions they would ask a customer. So that the trainer might follow the adviser's train of thought, the latter were asked to think out loud and explain their reasoning. This part of the simulation lasted eight minutes, followed by two minutes during which the advisers wrote the "contact" that they would leave in the information system in relation to this request. what he had understood about the case and how he would process it. The trainer then opened up a group discussion on the similarities and differences in ways to process the case and on any tips and advice. He would also ask questions identified during preparation with regard to the continuity of the processing and the transverse collective (if these points had not already been spontaneously raised). At this point the advisers compared the individual and collective practices used in their own respective CSCs and during request processing. This segment lasted 15 minutes, with an additional 5 minutes being devoted to pooling each adviser's "contact" (compiled and projected onto the wall) and to a new comparison of the writing and content of such information. fashion. As previously mentioned, we were not looking for correct processing; we wanted to identify the deep-rooted causes that might complicate the smooth running of the collective. We also wanted to highlight the coordination between the actors of the collective.

The sessions confirmed the importance of playing out the different cases individually before engaging in a collective discussion. Phase 1 allowed the advisers to project themselves into the action and to go beyond the discourse; phase 2 consisted of an exchange of views enriched by the individual reflections. Combined with the trainer's role, these conditions allowed each participant to freely express himself. 


\subsubsection{Part 2: simulation of the actual processing of a request} difficult. Had this already happened to them? Did it remind them of things in their dayto-day work? Did they have any explanations relevant to this real processing? And so on and so forth. The "contact" and the "commentaire" left in the information system by the advisers processing the request or resulting from automated processes (the internet in particular) were the object of specific discussions. As in the previous simulation, the trainer asked questions identified during the construction of the graphic representation.

65 In this part, the involvement of the advisers was different because the simulation consisted in showing them what had actually happened, whereas in the first simulation it was a case of what they themselves would have done. There was thus complementarity between these two parts, with the second part stabilising the vision of the transverse broached in part 1 via the facilitation. It also exposed the true nature of the request that had been played out in "segments" in the first part. Moreover, it revealed the customer's point of view regarding the entirety of a single request.

\subsubsection{The crucial role of the facilitation process in the collective sequences}

66 In addition to the conditions created to encourage freedom of expression (different CSC advisers for a given session, no management presence), the facilitation helped to establish an atmosphere of trust that stimulated discussion and ensured equal participation for all concerned. It played a vital role during the collective sequences 
because it made it possible to access the actors' cognitive thinking and to evoke the actual work done on a daily basis. During the first simulation, facilitation was an enormous help in revealing the transverse collective through the use of link elements during group discussions. The second simulation immediately placed the advisors in the transverse collective and led them to comment on a request that had been processed by other people. The risk was that they would stand back and adopt a "judgemental" stance. The facilitators' role was thus to involve them more by encouraging them to make the link with their everyday work.

Facilitation was managed by the researchers working on the research programme and the externality of their observation encouraged discussion. Although they knew a certain amount about the advisers' work, they were not experts, so the advisers were asked to not to use jargon and to avoid implicitness. There was thus a high level of explication during the discussions and this was appreciated by the advisers.

Finally, the facilitation made it possible to delve into certain areas of the advisers' activity that we had identified as important prior to the session, to directly react as and when subjects were raised during group discussions and to talk about the possible constraints regarding the time allowed for front-office or back-office activities, performance objectives, organisation, tools, etc.

\section{Results relating to the implementation of Transverse Reflexive Simulation}

\subsection{Representation of the transverse and transactional collective: a vision that advisers never see}

The objective of revealing the collective was achieved and the advisers liked having a global, concise and direct vision of request processing - something they had never had the opportunity to see before and which the graphic representation made possible. They appreciated being able to see the possible repercussions of some of their actions.

The graph was interesting, you realise that it starts with the client. You really need to be precise and thorough from the outset. And the smallest thing, like sending a letter which for us was not especially important to begin with, you realise it's important for the customer. That can help avoid a lot of call-backs (dual competency).

I'm thinking about the first adviser who doesn't even know what that led to later on and [...] that's the real reason why he called back (complaints expert).

The global and graphic vision that they saw differed from the logic of the tools they use on a daily basis and with which they have to attempt historical reconstructions. They rarely have the opportunity to get away from their tools and work on their craft. The graphic representation makes the object of their work concrete, by giving tangible form to the processing of the customer's request and its segmentation. The wall display and the place gradually taken by request foster this awareness.

It's even better on paper, it's better than saying on the SIMM pages, look, this stage here, this is what's going to happen, we run through it... and for the customer... that's what we have in mind... seeing it like that means we visualise it better than looking at SIMM, so then we are more vigilant (dual competency). 
7

This simulation gives meaning to their work by placing them and their contribution within a global process that has a before and an after and which includes contributions from other actors.

We know what to expect but it was really when I changed queue that that I realised

that the contact really was important (ongoing relationship).

They like having a clear vision of the contributions and interactions of all the "actors": the different advisers ("also it's clear that the advisers are different advisers"), the customer (so he (the customer) thinks he'll be able to sort things out with the technician but he won't sort anything out..."), the distributor and even the automated processes with which they are not always familiar.

Having feedback on the customer's experience and emotions throughout the processing of his/her request is completely new and very much appreciated. The advisers discover the customer along with the suppositions that he might make.

It is interesting to see the customer's emotions, we realise that he is going to imagine things that are not necessarily feasible. Seeing this side of the customer is useful (internet + dual competency).

\subsection{Transverse and transactional collective embedded in advisers' working practices}

The fact of working on elements facilitating processing continuity and fluidity made it possible to embed the transverse collective in the advisers' working practices. By using a real case as a basis for simulation we revealed certain issues (such as so-called "sudden unexplained" call transfers) which are potential sources of misunderstanding. Indeed, in such situations the customer's call is transferred to another adviser without any accompanying information, whereas the customer supposes the opposite and does not therefore repeat everything he has already said. Details that are vital to the next stage of processing are therefore missing and incorrect processing may occur.

The session work carried out on "contact" as a cooperative transitional object (Poret, 2015), was an important element in embedding the transverse collective in the advisers' working practices. Although this object is used by all advisers, nowadays it only has meaning during Ongoing Relationship work, i.e. when advisors have to work more on the next stage of the processing. Moreover, Transverse Reflexive Simulation has highlighted the absence of any clear status for the "contact" and its content: everyone appropriates it, notes it down and uses it in their own way. It might be used for continuity in request processing, or for self-protection in relation to the customer or the procedures to be followed, by giving details of certain specific elements, etc. The "contact" relating to a given request piles up and jumbles the different statuses, which can confuse or complicate the historical reconstruction required for the request to be understood. The exchanges between peers revealed points of view on the issue that were sometimes similar, sometimes disparate.

\subsection{A place of reflexivity and progression for the advisers}

Transverse Reflexive Simulation directly benefited adviser training not only in terms of transverse collective activity but also with regard to individual activity, collective craft 
and interactions with the customer. For various reasons there was total consensus between advisers.

They appreciated the rich nature of their discussions which had allowed them to update their knowledge, compare practices, exchange tips and tricks, etc. The fact that the discussions took place between peers, with no hierarchy, was unusual for them they were used to information being more top-down or prescriptive.

The discussions I had with colleagues from other agencies were really useful, in that while we are all customer advisers, we don't all work in the same way (complaints expert).

78 The advisers also pointed out the utility of working on a real case that has a value which cannot be compared to that of a fictional case that is hard to believe.

I liked that it was a real case because we realised all the stumbling blocks that exist when connecting customers. Every time, with every action, we always thought we were doing the right thing as advisers here at EDF, and this exercise showed us the consequences (complaints expert).

79 One of the major differences observed was the focus on their job rather than on the tool.

It's better (...) than looking at the SIMM pages ${ }^{7}$, which aren't really tangible. It's like, this is what is going to happen for the customer at this stage, in the process... I don't know everything, yet I'm not new, I know the job (dual competency).

The fact of going through the individual sequence before doing the collective sequence, the focus on freedom of expression, the role of the facilitators and the discussions between peers allowed some of the participants to feel more confident and express themselves, something they do not really do under normal circumstances. In this regard, one adviser told us how happy she was, because normally she never gives her point of view.

Yes, you have time to analyse, to learn all the details, and at the same time you have your own personal thing, what you are going to say, not when you are listening to everyone else. Well, okay, I'm going to say the same thing as him, I'm not going to worry about it, I'm not going to overthink it (...) Because me, usually, when there are lots of people, you don't hear a peep out of me, I stay in my corner. Even my team manager, she criticised me because in team meetings I don't say anything... If she saw me now she'd ask me what's going on! (...) Because I know I wouldn't have said anything, I'd have said, well, the same as her, and I'd have left it at that, so... You wouldn't have heard a peep out of me all day! But not here, no! I was relaxed. (Dual competency).

One important point was stressed because it is something that is often lacking, which was to reflect and to give the advisers time for that; because under normal circumstances they are constantly pressed for time. This "time bubble" gave them space to think about their own work and about the technical and organisational system.

To think about how to improve the process is halfway to solving the problem. And one very important notion for this type of workshop and for workshops in general is to give people time. I think that time allows you to think, to bring things into focus, to make a better analysis... but time is short for everyone; but in this case we were given time and I believe that there is a real benefit in that. (Complaints expert).

Transverse Reflexive Simulation thus had an immediate effect on the advisers during the sessions, but not just at that time. It also had an impact above and beyond the 
sessions themselves and the advisers who took part. Indeed, most of them took the graphic representation of the entire request process with them when they left and we know that it was used during a meeting by one complaints adviser when he returned to his Customer Service Centre. So Transverse Reflexive Simulation also has "'mediate' effects that operate after a temporal shift and that are diffused through the network to indirect beneficiaries" (Du Tertre, 2007, p13).

\subsection{An opportunity for continuous improvement to the process} performance and the conditions under which the work is done. We will cite just a few examples among those that were the subject of presentations and recommendations for improvement made to our business partners.

Discussions relating to real work done raised the issue of how performance assessment impacts the process, for example by revealing how the entanglement of indicators focused on immediate performance might hinder fluid and continuous processing; the tension that advisers sometimes have to deal with, between productivity and customer satisfaction; the search for immediate performance that can have negative effects on overall performance, etc. These results challenge the pertinence of certain indicators, particularly those that focus on "here and now" interaction, when the service relationship is located over a long time frame.

We highlighted certain characteristics of the technical and organisational system which do not result in fluid and continuous processing. In particular, we focused on the importance of the content of the "contact" and on how it takes on meaning over the process as a whole. In terms of contribution to design, this means not only training activities based on what was done during the simulation, but also contextual aids that might be provided when writing "commentaire".

This simulation, created to evoke actual work, demonstrated the impact and density of the contract opening stage, processed "on the go" (mobility) on the connection process and the repercussions it can have on the following stages of processing. It is this stage which drives the request process. Once again, this result has different possible outcomes in terms of design: to better adapt the computer tools, to offer training on the entire connection service and not just on one stage, particularly with regard to identifying the effect of such information on the subsequent stages of the process, etc.

Certain management principles were called into question, such as the fact that it is not possible to make an outgoing call when a telephone call has been cut off (something that is increasingly frequent with the use of mobile phones) even when the transaction had almost come to an end and the adviser only needs a few more minutes to finalise the request. The results would be positive for the customer, who would be happy to see himself treated with consideration with a call-back and his/her request reach a successful conclusion, for the adviser who wishes to do his job properly and satisfy the customer, and also for EDF in terms of collective efficiency that avoids a further call from the customer who would be dealt with by a different adviser who is unaware of the situation, thus leading to more time being spent. This result led to a revision of current practices and to a national redefinition of the conditions for calling back a customer. 

possible constitute more or less profound transformations. Changes to a customer callback policy can be very rapidly achieved, whereas the development of contextual aids for writing contact or more extensive modifications to the CRM software requires the creation of a think-tank. Regarding indicators, while some evolutions were readily accepted by our partners this was less true for others that called the performance measuring system into question. Following our presentations, our results and proposals for change are in the hands of our business team partners and of the various developers concerned (process, IS, training, etc.). To move forward, we are now considering the implementation of a test that will allow us to co-construct the service relationship with the advisers.

\section{Discussion}

\subsection{A space for the construction of continuity to serve service relationship engineering}

91 In our "service relationship engineering" technological research programme, Transverse Reflexive Simulation has two objectives. It is a question of simultaneously revealing the collective transverse that is still often ignored in current organisations, impacting the working conditions of those concerned, customer satisfaction and company performance; and detecting levers of transformation, based on research into the deep-rooted causes, so as to facilitate the service relationship and make it more fluid. To reach these two goals, we turned to forums for work-related debate (Casse \& Caroly, 2014; Rocha \& al, 2014; L'Allain \& al, 2015), discussion forums (Detchessahar \& al, 2010; Detchessahar, 2013) and other forums for comparing practices. We did this for two reasons: firstly, because the actors involved in customer request processing are usually dispersed throughout the process; in other words although they all take part in the collective construction of the response to the request, they do not intervene at the same time or in the same place and therefore rarely have the opportunity to talk with one another. Revealing the transverse collective therefore 
means doing away with this dispersal and bringing them together at the same time and place. course of the research programme studies enabled us to embed Transverse Reflexive Simulation engineering in an ontology and epistemology of dynamic, living, social and cultural complexity (Theureau, 1997). Like Detchessahar (2013) and Van Belleghem (2016), we believe that discussion alone does not suffice and can indeed be pointless if the space for debate or discussion is not the object of real engineering the main objective of which is to restore or "elicit" (Van Belleghem, ibid) the real work. Yet the fact of bringing together actors who are usually dispersed in time and space is a form of 
simplification that needs to be taken into account. In developing Transverse Reflexive Simulation using the results of previous studies on the work of advisers in natural situations, we were attempting to simulate the cognitive phenomena (Theureau, ibid) present during these natural situations (historical study, transmission and archiving, etc.). The aim was to reproduce these phenomena by simulating the specificities of natural situations, i.e. their temporal and spatial distribution, to which a technical and organisational distribution corresponds. Bringing the various actors of a given process together at the same time and place does not provide access to this precise knowledge, particularly with regard to the technical dimension.

In order to simulate the cognitive phenomena taking place during natural situations, it is necessary to have knowledge of the collective activity throughout the process, in its temporal and spatial distribution, and understand what cooperation across the organisation implies in terms of the activity of each of the actors involved at each stage. It is the studies carried out over the course of the research programme that allowed us to acquire the necessary technical and organisational knowledge, and more especially to highlight the crucial role of the "contact", with the existence of cooperative transitional tools (Poret, 2015; Poret \& al, 2016) at each stage allowing for a certain continuity of collective activity despite the discontinuity resulting from the different individual experiences. If we worked on "contact" with the advisers, it was absolutely thanks to this understanding of individual and collective activity throughout the process. This understanding also enabled us to provide a facilitation the role of which was crucial to achieving the dual objective of Transverse Reflexive Simulation and to build all of the background material needed for the simulation.

\subsection{A reflexive space to drive transformations}

Transverse Reflexive Simulation was designed as a space in which to build continuity a crucial element in any high-quality service relationship. The reflexivity at the heart of such spaces not only made it possible to reach the stated objectives, it also let us go even further by triggering individual and collective developments that would allow for transformations at different levels.

So just as Daniellou describes (2007) In relation to the results of ergonomic simulations of work situations, Transverse Reflexive Simulation offers formative and developmental benefits by comparing the worlds it furthers. Exchanges between peers with different profiles, from different Customer Service Centres, based on a comparison of individual practices led to the creation of a space for "professional multilingualism" (Duboscq \& Clot, 2010, p. 264), at the origin of a development that was not only personal, allowing each person to adopt a reflexive stance in relation to his/her own practices, but also interpersonal. In this respect Transverse Reflexive Simulation enables developments at the level of individual activity, at the level of collective professional activity (between peers) and at the level of transverse collective activity. It therefore constitutes a reflexive space that makes it possible to develop individuals, groups and the organisation (Mollo \& Nascimento, 2013).

Moreover, through its objective of transformation, Transverse Reflexive Simulation makes it possible to feed back elements relating to the factors that complicate or even prevent the realisation of the transverse collective activity and the customer's activity, impacting the continuity that is required for a high-quality service relationship. When 
they return to their posts, the advisers take these elements into account during the temporal and spatial distribution that characterises transversal processes that are more broadly diffused within their Customer Service Centres. They are also discussed by the researchers and operational management teams in order to propose avenues of transformation.

\section{Conclusion}

Through the transverse collective activity that it allows to be revealed and discussed, the methodology that we have presented in this article- Transverse Reflexive Simulation - constitutes a simulation of a process. In the race to optimise processes, there are proposals that exist to simulate them and hence predict the impact on overall performance of the transformations implemented as part of process re-engineering (Kim \& al, 2005; Doomun \& al, 2008; Shim \& al, 2010). These are digital simulations which model the process solely within the scope of a flow of information. Transverse Reflexive Simulation differs in that it adopts a new standpoint: that of the complexity of human activity. This leads to two major differences with digital simulations: it is a participative simulation focused on the work and the process is modelled as a coordination of individual activities that involves intra- and inter-professions. So when integrated into the everyday life of the organisation, due to its participative dimension Transverse Reflexive Simulation can lead to continuously renewed developments of the individual and collective activity at the origin of continuous improvement to the transverse performance. Specifically mobilised within the framework of process reengineering, Transverse Reflexive Simulation can make it possible to identify the impact of the planned transformations on the work and on the intra- and interprofession cooperation at the heart of this performance. In this respect it is a particularly useful performance lever based on human activity in a context of automated processes (Business Process Automation) because Transverse Reflexive Simulation makes it possible to predict how automation will impact the activity, in its individual and collective dimensions, and hence performance as a whole.

Moreover, Reflexive Simulation enhances the technological research programme and pertains to the company's sustainable transformation which began several years ago with our research programme. Transverse Reflexive Simulation shows that this sustainable transformation involves a different type of relationship with work and time: shifting from an individual performance logic that is managed over the short term and is potentially counter-productive, to a collective performance logic that involves, in particular, allowing time to talk about work. It is a question of using some of advisers' direct production time to open up spaces for building continuity, for improving skills, for developing individuals, groups and organisations, thus enabling the company to perform over the long term ( $\mathrm{Du}$ Tertre, 2013). In this respect, Transverse Reflexive Simulation and the research programme in which it is embedded are part of a sustainable transformation of the conceptualisation of performance that we propose to develop on the basis of human activity (Poret \& al, 2017).

The criteria of continuity and Transverse Reflexive Simulation defined within the framework of service relationship engineering are valid in other areas where the common characteristic is one that implies collective production that integrates different actors from the same professions, from different professions or from different 
companies, into a framework of a cooperation that is distributed in time and space. This is the case for goods and services the production of which involves cooperation that is both intra-organisational in relation to process and inter-organisational in respect of Supply Chains or inter-organisational networks. Nowadays, with companies refocusing on their core business and with the externalisation of other activities within partnership networks, "a large part of modern industrial activity (including services) involves recourse to chains of subcontractors that may have as many as eight or ten successive links" (Ségrestin, 2004, p.134). This configuration of distributed collective production places the issue of continuity at the heart of Supply Chain Management preoccupations (Coursaget \& al, 2014).

The pertinence of Transverse Reflexive Simulation in dealing with these questions that are common to many different areas, such as the simulation of processes and Supply Chain Management, opens up promising perspectives for research.

\section{BIBLIOGRAPHY}

Arnoud, J. (2013). Conception organisationnelle : pour des interventions capacitantes. . Paris : Thèse de doctorat du Conservatoire National des Arts et Métiers (CNAM).

Casse, C., \& Caroly, S. (2014). Concevoir un dispositif de Retour d'Expérience intégré à l'activité collective. 49ème Congrès de la SELF (La Rochelle), 327-335.

Coursaget, A., \& Tête, F. (2014). La continuité de la Supply Chain. Sécurité et stratégie, 3(18), 45-52.

Daniellou, F. (2007). Des fonctions de la simulation des situations de travail en ergonomie. Activités, 4(2), 77-83.

Detchessahar, M. (2013). Faire face aux risques psycho-sociaux : quelques éléments d'un management par la discussion. Négocitaions, 1(19), 57-80.

Detchessahar, M., Devigne, M., \& Stimec, A. (2010). Les modes de régulation du travail et leurs effets sur la santé des salariés : deux établissements d'accueil des personnes âgées en quête de management. Finance Contrôle Stratégie, 13(4), 39-74.

Doomun, R., \& Vunka Jungum, N. (2008). Business Process modelling, simulation and reengineering: call centres. Business Process Management Journal, 14(6), 838-848.

Du Tertre, C. (2005). Services immatériels et relationnels : intensité du travail et santé. Activités, 2(1), 37-49.

Du Tertre, C. (2007). "Modèle industriel" et "modèle serviciel" de performance. 17th International RESER Conference, Tampere (Finland), http://www.iddlab.org/data/sources/users/5/docs/ modele_industriel_et_modele_serviciel_de_performance.pdf.

Du Tertre, C. (2013). Economie servicielle et travail : contribution théorique au développement “d'une économie de la coopération". Travailler (29), 29-64. 
Duboscq, J., \& Clot, Y. (2010). L'autoconfrontation croisée comme instrument d'action au travers du dialogue : objets, adresses et gestes renouvelés. Revue d'anthropologie des connaissances, 4(2), 255-286.

Grosjean, M., \& Lacoste, M. (1999). Communication et intelligence collective. Le travail à l'hôpital. Paris : PUF, Le Travail Humain.

Groupe d'échange ICSI “Analyse d'Evènement”. (2013). Numéro Numéro 2014-04 des Cahiers de la Sécurité Industrielle, Institut pour une Culture de Sécurité Industrielle. Toulouse : ISSN 2100-3874.

Haradji, Y., \& Faveaux, L. (2006). Evolution de notre pratique de conception (1985-2005) : modéliser pour mieux coopérer à partir des critères d'utilité, d'utilisabilité. Activités, 3(1), 67-98.

Haué, J.-B. (2004). Intégrer les aspects situés de l'activité dans une ingénierie cognitive centrée sur la situation d'utilisation. @ctivités, 1(2), pp. 170-194. www.activites.org.

Kim, J.-I., Yim, D.-S., Choi, J.-S., \& Kim, K.-C. (2005). A methodology for integrating business process and simulation for business process redesign. Asian Journal on Quality, 6(1), 74-97.

L'Allain, C., Caroly, S., \& Drais, E. (2015). Les espaces de débat sur le travail : des ressources pour la prévention des risques dans un contexte d'innovations et d'incertitudes. Actes du 50ème Congrès de la Société d'Ergonomie de Langue Française (SELF), 316-322.

Lorino, P., \& Peyrolle, J.-C. (2005). Démarche pragmatiste et mise en processus dans les situations de gestion. Dans R. Teulier, \& P. Lorino, Entre connaissance et organisation : l'activité collective (pp. 220-229). Paris : La Découverte.

Mollo, V., \& Nascimento, A. (2013). Pratiques réflexives et développement des individus, des collectifs et des organisations. Dans P. Falzon, Ergonomie constructive (pp. 207-221).

Motté, F. (2012). Le collectif transverse : un nouveau concept pour transformer l'activité. Actes du 47ème Congrès de la Société d'Ergonomie de Langue Française (SELF), 102-108.

Motté, F., \& Haradji, Y. (2007). Le vendeur en ligne dans la relation de service. Dans M. Zouinar, G. Valléry, \& M.-C. Le Port, Ergonomie des produits et des services. XXXXIIe Congrès de la SELF, SaintMalo (pp. 257-265). Octarès.

Motté, F., \& Haradji, Y. (2010). Construire la relation de service en considérant l'activité humaine dans ses dimensions individuelles et collectives. Dans G. Valléry, M.-C. Le Port, \& M. Zouinar, Ergonomie, conception de produits et services médiatisés. Paris : PUF.

Motté, F., \& Lambert, I. (2008). S'appuyer sur l'analyse de l'activité pour concevoir une relation de service de qualité. Dans P. Negroni, \& Y. Haradji, Ergonomie et conception, 43ème Congrès de la SELF, Ajaccio (pp. 44-52). ANACT.

Petit, J., \& Dugué, B. (2013). Structurer l'organisation pour développer le pouvoir d'agir : le rôle possible de l'intervention en ergonomie. Activités, 10(2), 210-228.

Poizat, G., \& Durand, M. (2015). Analyse de l'activité humaine et éducation des adultes : faits et valeurs dans un programme de recherche finalisée. Revue française de pédagogie(190), 51-62.

Poret, C. (2011). L'articulation invisible des acteurs de la relation de service : une condition indispensable pour répondre à la demande du client. Séminaire Ergo'IdF (Cerf M., Motté F., Folcher V.), Entre continuité de la relation de service et discontinuité des activités : quelles contributions de l'ergonomie?, Paris, 18 octobre.

Poret, C. (2015). Concevoir pour le Pouvoir d'agir ensemble d'un collectif transverse. Le cas de la relation de service dans le domaine commercial. Thèse de doctorat - Université Paris VIII. 
Poret, C., Folcher, V., Motté, F., \& Haradji, Y. (2016). Concevoir pour le Pouvoir d'agir ensemble au sein des organisations : le cas d'un processus commercial. Activités, 13(2).

Poret, C., Motté, F., \& Leget, L. (2017). L'ergonomie au service de la performance commerciale de l'entreprise ? . 52ème Congrès de la SELF - Présent et Futur de l'Ergonomie (Toulouse, 20-22 septembre), 85-90.

Rocha, R., Mollo, V., \& Daniellou, F. (2014). Work debate spaces: A tool for developing a participatory safety management. Applied Ergonomics, 46, 107-114.

Ron, C. (2012). Analyse Approfondie d'Evènements (Recherche des causes profondes) ou Comment éviter la théorie de la pomme pourrie. Présentation powerpoint - www.asn.fr.

Salembier, P., \& Zouinar, M. (2004). Intelligibilité mutuelle et contexte partagé. Inspirations conceptuelles et réductions technologiques. Activités, 1(2), 64-85.

Segrestin, D. (2004). Les chentiers du manager. L'innovation en entreprise : où en sommes-nous? Comment piloter les changements et les maîtriser ? Paris : Armand Colin.

Shim, S. J., \& Kumar, A. (2010). Simulation for emergency care process reengineering in hospitals. Business Process Management Journal, 16(5), 795-805.

Strauss, A. (1992). La trame de la négociation. Paris : L'Harmattan.

Theureau, J. (1997). L'utilisation des simulateurs de salle de contrôle de réacteur nucléaire et de cockpit d'avion à des fins autres que de formation : présentation et discussion des tendances actuelles. Dans P. Béguin, \& A. Weill-Fassina, La simulation en ergonomie : connaître, agir et interagir (pp. 113-136). Toulouse : Octarès.

Theureau, J. (2004). Le cours d'action: Méthode élémentaire. Toulouse : Octarès.

Theureau, J. (2006). Le cours d'action : méthode développée. Toulouse: Octarès.

Van Belleghem, L. (2016). Eliciting activity: a method of analysis at the service of discussion. Le Travail Humain, 79(3), 285-306.

Varela, F. (1989). Invitation aux sciences cognitives. Paris : Editions du Seuil.

Veyne, P. (1971). Comment on écrit l'histoire. Paris : Editions du Seuil.

\section{NOTES}

1. Hereafter simply referred to as "advisers"

2. "Contact" and "commentaire" are terms used in the French application. They must therefore be retained here.

3. For example, the thesis showed how certain performance indicators, relating to each stage, could prevent the mobilisation of cooperative transitional instruments to help overall processing.

4. "Status of the sociotechnical system that created the conditions necessary for an event to occur. (...) we consider that a deep-rooted cause may stem from organisational or managerial dimensions and/or human factors." (ICSI "Event Analysis" exchange group, 2013, p18).

5. A "specific situation that takes into account human and organisational factors" (ibid, p.11)

6. "The Institute for a Culture of Industrial Safety" (ISCI) is an association under the 1901 law, the vocation of which is to advance the culture of safety in France. It was created in 2003 at the initiative of eight founding partners (Airbus, ArcelorMittal, CNRS, Communauté d'agglomération du Grand Toulouse, EDF, Institut National Polytechnique de Toulouse, Région Midi-Pyrénées and 
Total) who were rapidly joined by other industrial companies from various sectors, specialist institutes, schools and universities, actors from civil society (associations of mayors, trade union organisations, non-governmental organisations)." (Ibid, p.3)

7. This is the CRM software that the advisers use on an everyday basis.

\section{ABSTRACTS}

This article presents the genesis and implementation of a method that consisted in simulating the activity of processing a customer request in the field of the service relationship. The purpose of this simulation was twofold: to reveal a collective activity that unfolds in a distributed way in time and space and to identify the levers of transformation to facilitate the service relationship and make it more fluid. This simulation, known as "Transverse Reflexive Simulation", elicits the work thanks to the knowledge acquired on human activity in its various dimensions in an existing research programme in the $R \& D$ (Research and Development) division of a large company. It makes it possible to work on continuity, an element crucial to quality of service and customer satisfaction, by opening spaces for constructing this continuity. By promoting the development of individuals, collectives and organizations, Transverse Reflexive Simulation contributes to the company's long-term performance.

Cet article présente la genèse et la mise en œuvre d'une méthode qui a consisté à simuler l'activité de traitement d'une demande client dans le domaine de la relation de service. L'objectif de cette simulation était double: révéler une activité collective qui se déroule de façon distribuée dans le temps et dans l'espace et identifier des leviers de transformation pour faciliter et fluidifier la relation de service. Cette simulation, que nous avons nommée « Simulation Réflexive Transverse " convoque le travail par le biais des connaissances acquises sur l'activité humaine dans ses différentes dimensions au travers d'un programme de recherche technologique existant au sein de la R\&D (Recherche et Développement) d'une grande entreprise. Elle permet ainsi de travailler sur la continuité, élément crucial de la qualité de service et de la satisfaction client, en ouvrant des espaces de construction de cette continuité. En favorisant le développement des individus, des collectifs et des organisations, la Simulation Réflexive Transverse contribue à la performance de l'entreprise sur le long terme.

\section{INDEX}

Mots-clés: simulation d'activité humaine ; activité collective transverse; relation de service; conception; modélisation.

Keywords: simulation of human activity; cross-functional collective activity; service relationship; design; modelling. 


\section{AUTHORS}

\section{FLORENCE MOTTÉ}

EDF R\&D. EDF Lab Paris-Saclay. 7, boulevard Gaspard Monge 91120 Palaiseau.

florence.motte@edf.fr

\section{CÉLINE PORET}

Université Paris 8 - CiTU Paragraphe. ComUE Paris Lumières. 2 rue de la liberté 93526 Saint Denis cedex.poret_celine@yahoo.fr 